ARTICLE

DOI: $10.1038 / \mathrm{s} 41467-017-02590-1$

OPEN

\title{
Ceramic nanowelding
}

\author{
Liqiang Zhang ${ }^{1}$ Y Yushu Tang ${ }^{1}$, Qiuming Peng ${ }^{2}$, Tingting Yang², Qiunan Liu², Yuecun Wang², \\ Yongfeng $\mathrm{Li}^{1}$, Congcong $\mathrm{Du}^{2}$, Yong Sun ${ }^{2}$, Lishan Cui ${ }^{1}$, Fan Yang ${ }^{1}$, Tongde Shen (1) ${ }^{2}$, \\ Zhiwei Shan $\mathbb{D}^{3} \&$ Jianyu Huang ${ }^{2}$
}

Ceramics possess high temperature resistance, extreme hardness, high chemical inertness and a lower density compared to metals, but there is currently no technology that can produce satisfactory joints in ceramic parts and preserve the excellent properties of the material. The lack of suitable joining techniques for ceramics is thus a major road block for their wider applications. Herein we report a technology to weld ceramic nanowires, with the mechanical strength of the weld stronger than that of the pristine nanowires. Using an advanced aberration-corrected environmental transmission electron microscope (ETEM) under a $\mathrm{CO}_{2}$ environment, we achieved ceramic nanowelding through the chemical reaction $\mathrm{MgO}+\mathrm{CO}_{2} \rightarrow \mathrm{MgCO}_{3}$ by using porous $\mathrm{MgO}$ as the solder. We conducted not only nanowelding on $\mathrm{MgO}, \mathrm{CuO}$, and $\mathrm{V}_{2} \mathrm{O}_{5}$ nanowires and successfully tested them in tension, but also macroscopic welding on a ceramic material such as $\mathrm{SiO}_{2}$, indicating the application potential of this technology in bottom-up ceramic tools and devices.

\footnotetext{
${ }^{1}$ State Key Laboratory of Heavy Oil Processing, and Department of Materials Science and Engineering, China University of Petroleum, Beijing 102249, China. ${ }^{2}$ Nano Energy Center, State Key Lab Metastable Materials Science and Technology, Yanshan University, Qinhuangdao 066004, China. ${ }^{3}$ Center for Advancing Materials Performance from the Nanoscale (CAMP-Nano) \& Hysitron Applied Research Center in China (HARCC), State Key Laboratory for Mechanical Behavior of Materials, Xi'an Jiaotong University, Xi'an 710049, China. Correspondence and requests for materials should be addressed to Y.L. (email: yfli@cup.edu.cn) or to Z.S. (email: zwshan@mail.xjtu.edu.cn) or to J.H. (email: jhuang@ysu.edu.cn)
} 
A lthough many nanomaterials have been fabricated ${ }^{1-3}$, how to join them together to produce more complicated nanodevices 4,5 by using nanowelding is still challenging ${ }^{6,7}$. Welding at the nanoscale is crucial to build nanodevices via the bottom-up approach ${ }^{8}$. 9 . In recent years, scientists have successfully realized the joining of individual lowdimensional nanostructure materials including carbon nanotubes $(\mathrm{CNTs}) / \mathrm{metal}^{10}, \mathrm{CNTs} / \mathrm{CNTs}^{11}$, and metal $/$ metal $^{12,13}$, by either cold welding ${ }^{14}$, Joule heating ${ }^{15}$, or applying voltage/current ${ }^{16}$. Each welding technique has its special advantages, such as high speed, low cost, no contamination, no damage or an excellent weld junction. However, the reported techniques are mainly restricted to the welding of either CNTs or metals, and the welding of ceramic nanomaterials is seldom reported. Till now, ceramic nanomaterials can only be welded by depositing metal Pt, $\mathrm{Au}, \mathrm{Sn}$ on the junction through heating or focused ion beam $(\mathrm{FIB})^{17}$, which is not only expensive and complex, but also contaminates and even damages the sample during the welding process ${ }^{18}$. Additionally, the poor infiltration between ceramic and metal makes it difficult to form a good joint. Furthermore, joining ceramic nanomaterials by using metal causes serious internal stress due to large thermal expansion coefficients mismatch. As we know, an ideal welding technique usually selects the same type of material as the solder, which can preserve its original properties and morphology without causing compatibility problems. This goal is hard to achieve for ceramic welding given the high melting point and good insulation of ceramic materials. Additionally, ceramic nanomaterials usually possess high hardness, no deformability and low diffusivity, which all lead to the extreme difficulty of ceramic nanowelding ${ }^{19}$. Developing a technique by using a ceramic as the solder for welding ceramics is therefore the ultimate goal for the nanowelding of ceramics. Ceramic welding is important for making more complex structures that are impractical or impossible to make using one-step processing.

$\mathrm{MgO}$ is widely used as an adsorbent for the capture of greenhouse gas $\left(\mathrm{CO}_{2}\right.$ gas ${ }^{20}$. It was recently found that electron or plasma irradiation can promote a chemical conversion of $\mathrm{CO}_{2}{ }^{21,22}$, which inspired us to explore the possibility of using the electron beam (e-beam) to stimulate the $\mathrm{MgO}$ and $\mathrm{CO}_{2}$ reaction for ceramic nanowelding applications.

We conducted experiments in an advanced Cs image corrected environmental transmission electron microscope (ETEM) under the flow of $\mathrm{CO}_{2}$ gas. Under e-beam irradiation in the $\mathrm{CO}_{2}$ environment, nano-MgO reacts with $\mathrm{CO}_{2}$ quickly without any external heating source or current. The irradiated area becomes fluidic with gas bubbles erupting violently and continuously, mimicking the boiling of viscous gels. By using this technique, we welded $\mathrm{MgO}, \mathrm{CuO}$, and $\mathrm{V}_{2} \mathrm{O}_{5}$ nanowires in the ETEM and carried out successful in situ tensile tests on these nanowires. Compared with traditional welding technologies, this technology achieves a full ceramic nanoweld using a ceramic solder, which is simple, low cost, high speed and without contamination. Most importantly, the welding spots exhibit a remarkable tensile strength that is even greater than that of the pristine nanowires.

\section{Results}

In situ nanowelding of ceramic nanowires in an ETEM. The nanowelding process is shown schematically in Fig. 1a. We conducted nanowelding of $\mathrm{MgO}$ nanowires by using a PicoFemto transmission electron microscope and a scanning tunneling microscopy (TEM-STM) holder (Fig. 1b) in a Cs-corrected FEI Titan ETEM. MgO nanowires were first glued on two tungsten (W) tips by using silver epoxy (Fig. 1a). Subsequently two individual $\mathrm{MgO}$ nanowires were manipulated toward each other by the movable piezoelectrics-controlled STM probe to carry out the welding experiments (Fig. 1a). To test the feasibility of the ceramic nanowelding, we first attempted to weld one $\mathrm{MgO}$ nanowire onto the $\mathrm{W}$ tip (the 1st welding). The connection between the $\mathrm{W}$ tip and the $\mathrm{MgO}$ nanowire was made in a headto-head geometry (Fig. 2a). When the two nanowires come into intimate contact, pure $\mathrm{CO}_{2}$ gas was released into the ETEM chamber. As the pressure of the $\mathrm{CO}_{2}$ in the chamber reached 200 $\mathrm{Pa}$, we focused the e-beam onto the nanowire junction with a medium dose rate $\left(100 \mathrm{e} \mathrm{nm}^{-2} \mathrm{~s}^{-1}\right)$. The e-beam dose rate plays a significant role in the speed of the welding (Supplementary Fig. 1). It was observed that a large amount of highly mobile bubbles emerged in the interior of the irradiated $\mathrm{MgO}$ nanowire, and the number and size of the bubbles grew with time (Supplementary Fig. 2 and Supplementary Movie 1). With increasing bubble number and size, the nanowire became fluidic and flowed like a porous viscous liquid. Upon reducing the e-beam intensity, the $\mathrm{W}$ tip and the $\mathrm{MgO}$ nanowire were welded together instantly (Fig. 2b, j). Besides the head-to-head welding mode, the welding could be performed in a side-by-side mode as well (Supplementary Fig. 3). Once the welding process completed, the $\mathrm{CO}_{2}$ was removed from the ETEM chamber. After that, we found that the $\mathrm{MgO}$ nanowire was firmly welded onto the $\mathrm{W}$ tip, and the aswelded $\mathrm{MgO}$ nanowire retained its original morphology (Fig. 2b). To test the quality of the welding, we pulled the nanowire backward and found that the nanowire broke near the right contact rather than from the welding joint (Fig. 2c), proving that the tensile strength of the weld is greater than that of the pristine $\mathrm{MgO}$ nanowire.

After the first welding ( $\mathrm{MgO}$ welding onto the $\mathrm{W}$ tip), we welded a second $\mathrm{MgO}$ nanowire (2nd welding) to the first nanowire residue attached to the $\mathrm{W}$ tip. Similar joining behavior to the first welding was also obtained (Fig. $2 \mathrm{~d}-\mathrm{f}, \mathrm{k}$ ). We then pulled the two welded nanowires backward, and the nanowire broke near the right contact, proving again that the tensile strength of the welding joints 1 and 2 is greater than that of the pristine $\mathrm{MgO}$ nanowire. A third nanowire was welded to the two nanowires attached to the $\mathrm{W}$ tip (Fig. $2 \mathrm{~g}-\mathrm{i}, \mathrm{l}$ ). As we pulled this

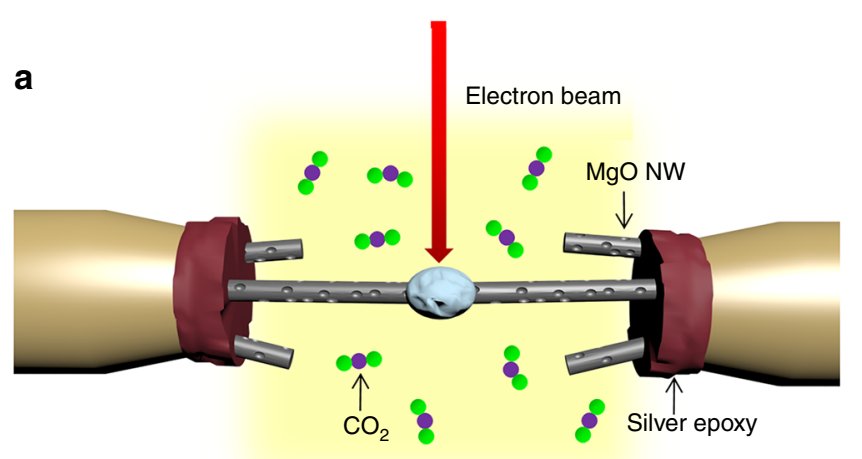

b

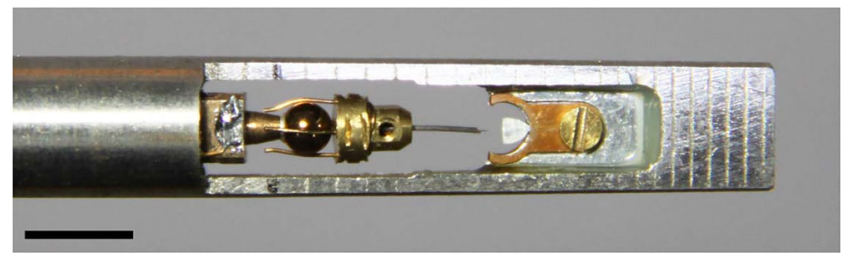

Fig. 1 Schematics of the ceramic nanowelding setup. a The experiment was carried out in an ETEM with an atmosphere of $\mathrm{CO}_{2}$. Prior to the experiment, several $\mathrm{MgO}$ nanowires were first glued to two $\mathrm{Al}$ probes using silver epoxy, and then were manipulated to approach each other using a STM holder. $\mathbf{b}$ The real image of the STM holder utilized in this study. Scare bar $=0.5 \mathrm{~cm}$ 
nanowire backwards, it broke near the right contact of the third nanowire, not from the welding joints, proving again that the tensile strength of the welds is greater than that of the pristine $\mathrm{MgO}$ nanowire. Additionally, we did not see changes or slippage of the contact during all the tensile testing experiments, indicating the mechanical robustness of the contact.

Under the flow of $\mathrm{CO}_{2}$ gas into the ETEM chamber and by focusing the e-beam to the nanowire junctions, nanowelding of ceramic nanowires was successful (Fig. 2, Supplementary Fig. 4 and Supplementary Movie 2). No extra heating or application of voltage/current is required, and the entire nanowelding process can be completed with both $\mathrm{CO}_{2}$ and e-beam (Supplementary Fig. 5). All of the three weld junctions exhibit smooth surfaces without voids (Fig. 2j-l), representing the typical characteristics for a good weld. We have done identical welding tests for $\mathrm{MgO}$ nanowires with different diameters. There appears to be no limits in terms of the diameter for the welding of nanowires (Supplementary Fig. 6). Beside $\mathrm{MgO}$ nanowires, other types of ceramic nanowires with different diameters could also be welded together using this technique (Supplementary Fig. 7).

Structure evolution of the nanowelds. The welding process was monitored by TEM bright-field imaging, electron diffraction pattern (EDP) and electron energy loss spectroscopy (EELS) (Fig. 3). The pristine $\mathrm{MgO}$ nanowires fabricated through a hydrothermal method are porous and polycrystalline (Fig. 3a, e, i and Supplementary Fig. 8). Upon e-beam irradiation for several minutes (Fig. 3b), the original $\mathrm{MgO}$ gradually transformed from polycrystalline (Fig. 3a, e, i) into an amorphous structure (Fig. 3b, $\mathrm{f}, \mathrm{j}, \mathrm{c}, \mathrm{g}, \mathrm{k}$ ). During the phase transition, a large number of nano bubbles were generated (Fig. 3f, g and Supplementary Figs 2 and
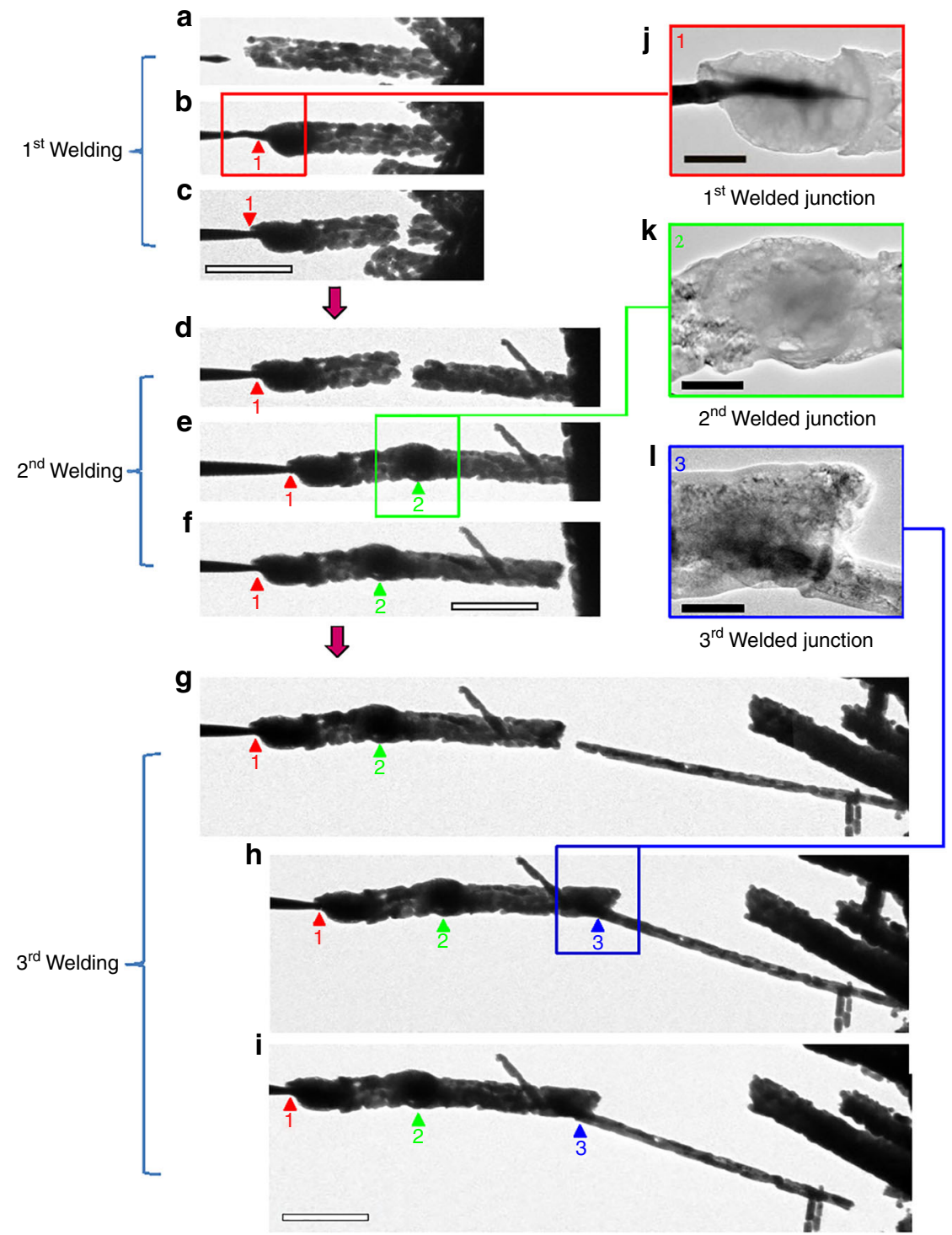

Fig. 2 The welding process of the ceramic $\mathrm{MgO}$ nanowires. Arrowheads and the numbers underneath them point out the welding spots. a-c The first welding is the process of welding an $\mathrm{MgO}$ nanowire to the $\mathrm{W}$ tip. a A W tip approaching an $\mathrm{MgO}$ nanowire. $\mathbf{b}$ The $\mathrm{MgO}$ nanowire was welded to the $\mathrm{W}$ tip. c Tensile test on the $\mathrm{MgO}$ nanowire welded to the $\mathrm{W}$ tip. The $\mathrm{MgO}$ nanowire broke near the right contact. $\mathbf{d}$-f The second welding: $\mathbf{d}$ The first nanowire welded to the W tip approaching a second $\mathrm{MgO}$ nanowire. e The second $\mathrm{MgO}$ nanowire welded together with the first one. $\mathbf{f}$ The second nanowire broke near the right contact upon tensile loading. $\mathbf{g}$-i The third welding: $\mathbf{g}$, the first and second welded nanowires approaching a third nanowire; $\mathbf{h}$ The nanowire welded to a third nanowire; $\mathbf{i}$ The third nanowire broke near the right contact upon tensile loading. $\mathbf{j}, \mathbf{k}, \mathbf{I}$ Magnifications of the boxed region in $\mathbf{b}$, $\mathbf{e}$ and $\mathbf{h}$, respectively, showing the morphologies of the welded spots. Scale bars: (a-i) $5 \mu \mathrm{m} ;(\mathbf{j}-\mathbf{I}) 200 \mathrm{~nm}$ 
5). These tiny bubbles gradually merged into large bubbles and migrated quickly toward the nanowire edge (Fig. $3 \mathrm{~g}$ ), while new bubbles were continuously generated, forming a porous structure in the nanowires (Fig. 3c, g). After 16 minutes of reaction, the sharp angular edges of the two $\mathrm{MgO}$ nanowires (Fig. 3b) became blurred and the two nanowires were welded together (Fig. 3c, g and Supplementary Fig. 9). EDPs (Fig. 3i-k) and EELS (Fig. 3m, $\mathrm{n}$ ) indicate that the reaction product in the welding spot was amorphous $\mathrm{MgCO}_{3}$. With the presence of $\mathrm{CO}_{2}$, the $\mathrm{MgCO}_{3}$ obtained immediately after reaction was similar to a glue, and could be significantly stretched, displaying superplasticity (Supplementary Fig. 10 and Supplementary Movie 3). However, with increasing time, it solidified with many nanobubbles embedded in it (Supplementary Fig. 11). E-beam has an important effect on the mechanical behavior of the amorphous $\mathrm{MgCO}_{3}$. With intense ebeam irradiation, the as-formed $\mathrm{MgCO}_{3}$ was very ductile and showed a ductile fracture feature; when the beam was turned off, it became brittle (Supplementary Fig. 11).

Voids existing in the welding junction is detrimental to the mechanical strength of a weld (Supplementary Fig. 12 and Supplementary Movie 4). Thus, after finishing the welding (Supplementary Movie 5), the $\mathrm{CO}_{2}$ was pumped out of the ETEM chamber to drive out the bubbles (Fig. 3d and Supplementary Movie 6). Under e-beam irradiation without the $\mathrm{CO}_{2}$ gas, the nanobubbles in the amorphous $\mathrm{MgCO}_{3}$ gradually disappeared (Fig. $3 \mathrm{~d}, \mathrm{~h}$ ), and the original porous, amorphous $\mathrm{MgCO}_{3}$ (Fig. 3c, g, k) gradually transformed into a dense nanocrystalline material (Fig. 3h, Supplementary Fig. 13 and Supplementary Movie 6). The EDP (Fig. 3l) and the EELS results (Fig. $3 \mathrm{~m}, \mathrm{n}$ ) indicated that these tiny nanocrystals were $\mathrm{MgO}$ (JCPDS card No. 30-0794), which originated from the decomposition of $\mathrm{MgCO}_{3}$. Although the nanocrystalline $\mathrm{MgO}$ generated after welding had the same elemental composition as the pristine $\mathrm{MgO}$, the grain size of the former was much smaller than the latter. It is well known that nanocrystalline materials usually demonstrate excellent mechanical properties ${ }^{23,}{ }^{24}$, thus ensuring the excellent mechanical properties on the weld junction, which has already been confirmed from Fig. 2. The above welding technology can be extended to $\mathrm{MgO}$ nanosheets (Supplementary Fig. 14) and $\mathrm{CaO}$ nanoparticles (Supplementary Fig. 15).

The most interesting phenomenon in this study is the melting behavior of MgO. It is well known that the melting point of ceramic $\mathrm{MgO}$ is very high $\left(2852^{\circ} \mathrm{C}\right)$, however, it showed a melting behavior under the e-beam irradiation in the $\mathrm{CO}_{2}$ environment without any external heating. The melting behavior is not directly the melting of $\mathrm{MgO}$ but is associated with a chemical reaction between the $\mathrm{MgO}$ and the $\mathrm{CO}_{2}$, i.e.

$$
\mathrm{MgO}+\mathrm{CO}_{2} \rightarrow \mathrm{MgCO}_{3}
$$

Reaction (1) is exothermic with $\Delta H=-118 \mathrm{~kJ} / \mathrm{mol}^{25}$. As $\mathrm{MgO}$ and $\mathrm{MgCO}_{3}$ are superior thermal insulating materials, most of the released heat from this reaction can be completely absorbed, which can raise the temperature of $\mathrm{MgCO}_{3}(1 \mathrm{~mol})$ from room temperature to $1560 \mathrm{~K}(\Delta T=\Delta H / C=118000 / 75.6=1560 \mathrm{~K})$ by referring to its specific heat capacity: $\mathrm{C}=75.6 \mathrm{~J} /(\mathrm{mol} \mathrm{K})$. The melting point of $\mathrm{MgCO}_{3}$ is only $873-1173 \mathrm{~K}$. Thus, it is understandable that $\mathrm{MgCO}_{3}$ demonstrated an obvious melting behavior. Under normal conditions, there exists an energy barrier for the $\mathrm{MgO}$ to react with $\mathrm{CO}_{2}$, and this reaction cannot occur automatically, but in this study, reaction (1) was activated by the e-beam irradiation. After evacuating the $\mathrm{CO}_{2}$ and under e-beam irradiation, $\mathrm{MgCO}_{3}$ decomposed back into $\mathrm{MgO}$ via the following reaction:

$$
\mathrm{MgCO}_{3} \rightarrow \mathrm{MgO}+\mathrm{CO}_{2}
$$

Thus in the whole welding process, $\mathrm{MgCO}_{3}$ only played a transitional role. We reduced the melting temperature of the solder material through the carbonation of $\mathrm{MgO}$, realizing a true ceramic nanowelding by using ceramic without any other external heat or current.

E-beam and $\mathrm{CO}_{2}$ are the two prerequisites for realizing the ceramic nano welding. Both $\mathrm{CO}_{2}$ and $\mathrm{MgO}$ were activated under high dose e-beam irradiation. For the $\mathrm{CO}_{2}$, the predominant ions formed on irradiation are $\mathrm{CO}_{2}{ }^{+}, \mathrm{CO}^{+}, \mathrm{CO}, \mathrm{O}^{+}, \mathrm{O}_{2}{ }^{+}, \mathrm{C}^{+}$etc ${ }^{26}$. While for the $\mathrm{MgO}$, the $\mathrm{Mg}$ atoms and $\mathrm{MgO}$ molecules in the irradiated area are charged positively as $\mathrm{Mg}^{+}$and $(\mathrm{MgO})^{+}$, respectively ${ }^{27}$. Due to the formation of highly reactive products as a result of the radiolysis process, the reaction between $\mathrm{MgO}$ and $\mathrm{CO}_{2}$ occurred in the ETEM. No external heat source or current are needed for the welding.

Practical applications of the ceramic nanowelding technology. Nanomaterials such as nanowires are building blocks of future electronic devices, and evaluating their mechanical properties is crucial but challenging. For example, measuring the tensile strength of individual nanowires is very challenging due to the difficulty in making robust mechanical contact to fix the nanowires to a testing device ${ }^{28}$. One way to fix the ceramic nanomaterials on a TEM chip for in situ test is through FIB manipulation ${ }^{29}$. Although the recent innovative cold welding technique displays a good performance for the welding of metal nanowires ${ }^{14}$, it is unsuitable for the welding of nano ceramics.

In this study, we completed the welding of ceramic nanomaterials through a chemical reaction, in which the typical ceramic $\mathrm{MgO}$ was used as the solder. For evaluating the detailed mechanical properties of the weld junction, we created a selfassembled in situ TEM-atomic force microscopy (AFM) device to carry out the tensile test, as illustrated in Fig. 4a. The real image of the experimental setup is shown in Fig. $4 \mathrm{~b}$. In order to study the mechanical properties of the pure $\mathrm{MgO}$ nanocrystals on the weld junction, we first welded the $\mathrm{W}$ tip coated with some pure $\mathrm{MgO}$ nanocrystal onto the tip of the AFM cantilever. When stretching the $\mathrm{W}$ tip, the weld junction comprised of nanocrystalline $\mathrm{MgO}$ moved forward along the same direction, while the AFM cantilever was bent (Supplementary Fig. 16). After stretching $363 \mathrm{~nm}$, the nanocrystalline $\mathrm{MgO}$ junction broke and the fracture surface displayed a brittle fracture characteristic (Supplementary Movie 7). The detailed tensile strain value of nanocrystalline $\mathrm{MgO}$ can be calculated through measuring the deflection of the AFM cantilever. According to the formula $\mathrm{F}=\mathrm{K} \cdot \Delta \mathrm{X}$, where $\mathrm{F}$ is the force, $\mathrm{K}$ is the force constant, and $\Delta \mathrm{X}$ is the displacement of the AFM cantilever, the tensile strength of the $\mathrm{MgO}$ nanocrystals on the weld junction reached as high as $2.8 \mathrm{GPa}$. This value is much higher than that of most of the welds using conventional solder materials, such as metals (Cu: 210 MPa, Iron: $350 \mathrm{MPa}$, Al: 40 $\mathrm{MPa})^{30}$ and silver glue $(\sim 20 \mathrm{MPa})$, which demonstrates its superior advantages for welding. Additionally, after the tensile test, we flowed $\mathrm{CO}_{2}$ gas into the ETEM chamber and attempted to weld the fractured welding junction, and the fractured welds were fully rewelded (Supplementary Fig. 17), showing a great potential of the application of the current welding technology in the repairing of ceramic materials.

This ceramic nanowelding technology can enable in situ TEM tensile testing of other nanowire systems. For instance, we have firstly tested the tensile properties of ceramic $\mathrm{MgO}$ nanowires by using this technique (Fig. 4c). In the experiment, one pristine 

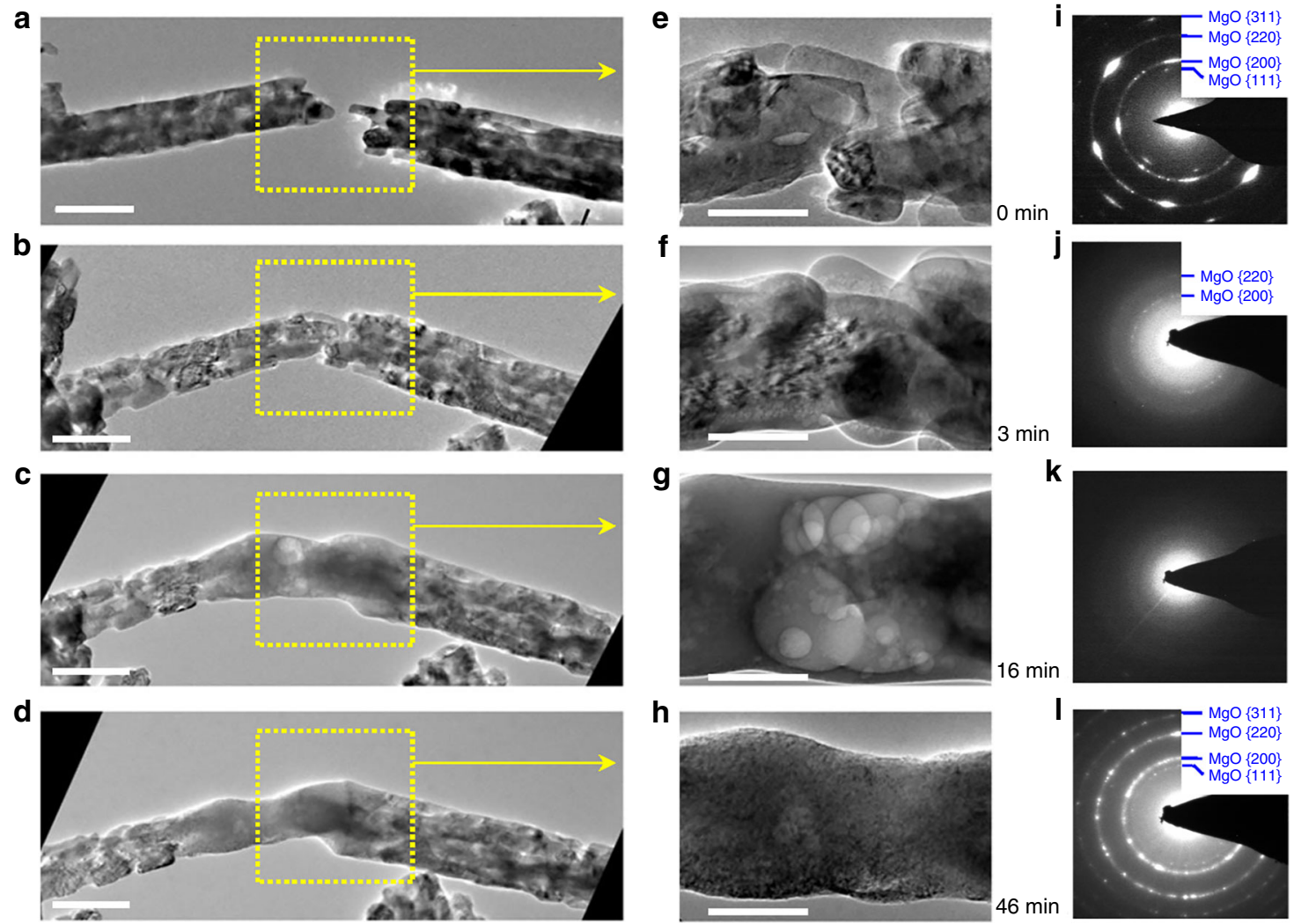

h
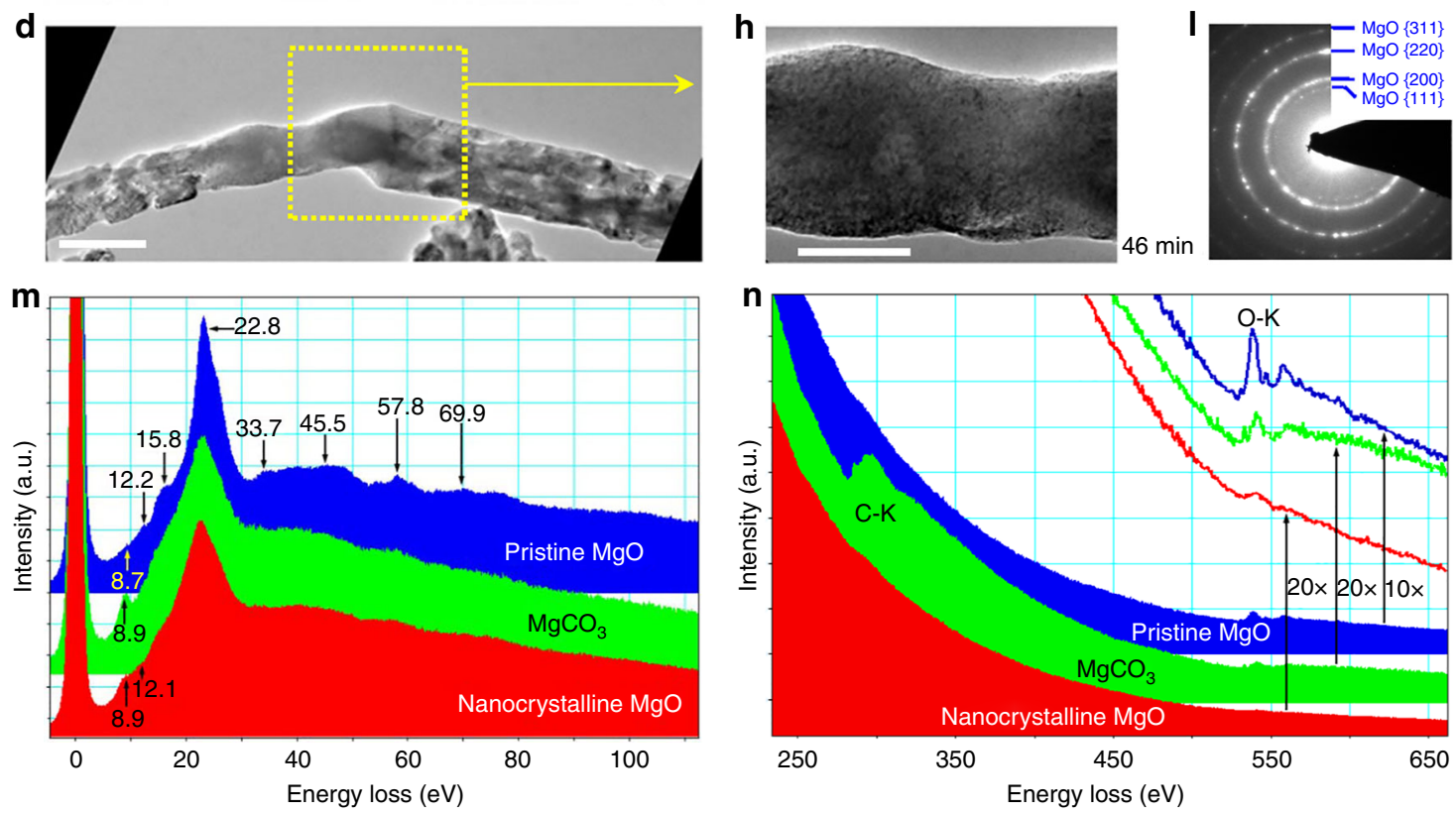

Fig. 3 Structure evolution of the nanowelding process. $\mathbf{a}$, e Two $\mathrm{MgO}$ nanowires brought into close proximity prior to the welding. $\mathbf{b}, \mathbf{f}$ Upon connecting the two $\mathrm{MgO}$ nanowires, $\mathrm{CO}_{2}$ is pumped into the ETEM chamber. Under e-beam irradiation in a $\mathrm{CO}_{2}$ environment, the $\mathrm{MgO}$ carbonation reaction starts immediately. $\mathbf{c}, \mathbf{g}$ The two $\mathrm{MgO}$ nanowires welded together. Plenty of voids were found in the weld. $\mathbf{d}, \mathbf{h}$ After removing $\mathrm{CO}_{2}$ from the ETEM chamber and continuing irradiation on the welded spot, the microstructure of the weld spot changes from grey amorphous contrast to nanocrystalline. $\mathbf{c}, \mathbf{g}$ Plenty of nano-pores exist in the $\mathrm{MgO}$ after irradiation in the $\mathrm{CO}_{2}$ environment for $3 \mathrm{~min}$. The sharp diffraction rings from the pristine $\mathrm{MgO}$ (i) become dim, and the amorphous content gradually increases $(\mathbf{j}, \mathbf{k})$. h The bubbles in the $\mathrm{MgCO}_{3}$ gradually disappear, and in the end, the original porous, amorphous $\mathrm{MgCO}_{3}$ transforms into a dense nanocrystalline $\mathrm{MgO}(\mathbf{I}) . \mathbf{m}, \mathbf{n}$ Low-loss and core-loss EELS from the pristine $\mathrm{MgO}, \mathrm{MgCO}_{3}$ and the nanocrystalline $\mathrm{MgO}$ originate from the decomposition of $\mathrm{MgCO}_{3}$. The pristine $\mathrm{MgO}$ shows seven characteristic low-loss peaks at 12.2, 15.8, 22.8, 33.7, 45.5, 57.8 and 69.9 eV. The peaks at 532 and $538 \mathrm{eV}$ arise from the $\mathrm{O}-\mathrm{K}$ edge. Note that $\mathrm{C}$ is only present in the $\mathrm{MgCO}_{3}$ (green profile in $\mathbf{n}$ ), which is not found in the pristine $\mathrm{MgO}$ (blue plot in $\mathbf{n}$ ) and the nanocrystalline $\mathrm{MgO}$ (red plot in $\mathbf{n}$ ). Scale bars: (a-d) $500 \mathrm{~nm}$; (e-h) $200 \mathrm{~nm}$

$\mathrm{MgO}$ nanowire was first welded onto the $\mathrm{W}$ tip, and then this nanowire was welded to another $\mathrm{MgO}$ nanowire with a much larger diameter. After they were firmly welded together, we pulled the $\mathrm{W}$ tip backward, and the entire sample moved along the tensile direction. Due to the ultrahigh mechanical strength of the weld junction, the $\mathrm{MgO}$ nanowire with a small diameter broke in the middle (Fig. 4c and Supplementary Movie 8). In this process, the $\mathrm{W}$ tip moved $1.05 \mu \mathrm{m}$. Referring to the area of the fracture surface, we calculated that the tensile strength of the $\mathrm{MgO}$ nanowire to be $261 \mathrm{MPa}$ (much lower than that of the nanocrystalline $\mathrm{MgO}$ ).

In addition to $\mathrm{MgO}$ nanowires, we also carried out several tensile experiments for single crystal CuO (Fig. 4d, Supplementary Figs 18 and 19 and Supplementary Movie 8) and single crystal $\mathrm{V}_{2} \mathrm{O}_{5}$ nanowires (Supplementary Figs 20 and 21 and Supplementary Movie 8) in the ETEM by using this technique. It is calculated that the tensile strength of the $\mathrm{CuO}$ nanowire is 2.3 $\mathrm{GPa}$, and that of the $\mathrm{V}_{2} \mathrm{O}_{5}$ nanowire is $1.6 \mathrm{GPa}$. It should be noted 
a
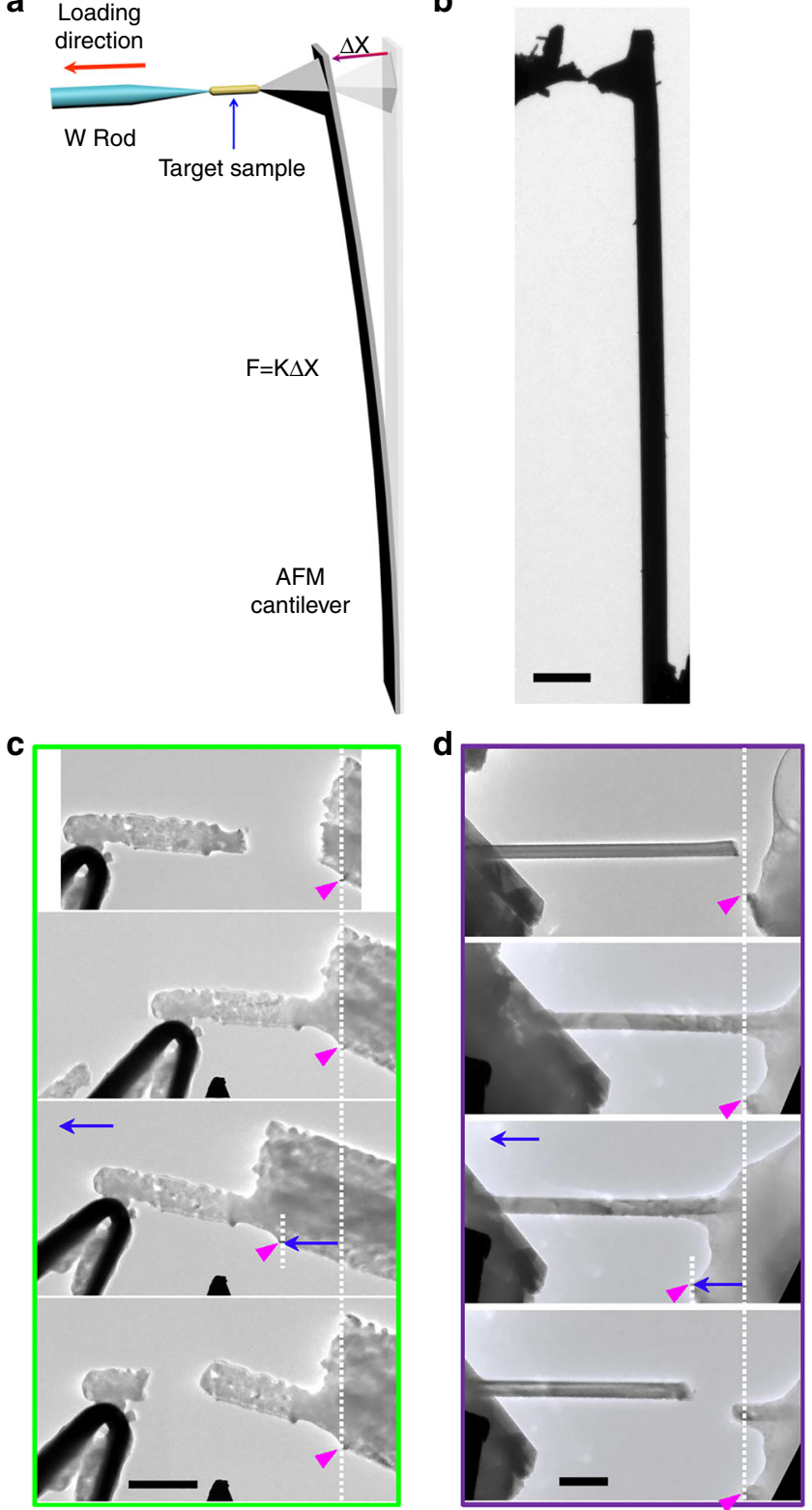

Fig. 4 In situ tensile tests of ceramic nanowires using ceramic nanowelding. a The schematic of a self-assembled in situ TEM-AFM device for the tensile test. The target sample was first welded to the $\mathrm{W}$ tip, and then welded to the tip of the AFM cantilever. We stretched the $W$ tip, and the welded sample moved along the same direction, meanwhile the AFM cantilever was bent. Through measuring the deflection of the AFM cantilever, we can calculate the tensile strength of the sample. $\mathbf{b}$ A real image of the experiment setup. c The tensile test for the pristine $\mathrm{MgO}$ nanowires, and the maximum moving distance of the $\mathrm{W}$ tip is $1 \mu \mathrm{m}$. The weld junction is composed of nanocrystalline $\mathrm{MgO}$. d The tensile test for a ceramic CuO nanowire, and the maximum moving distance of the $W$ tip is $228 \mathrm{~nm}$. Scale bars: (b) $10 \mu \mathrm{m}$; (c) $1 \mu \mathrm{m}$; (d) $200 \mathrm{~nm}$

that both the tested $\mathrm{CuO}$ and the $\mathrm{V}_{2} \mathrm{O}_{5}$ nanowires are single crystals (Supplementary Figs 18 and 20), and they both broke from locations other than the welding spots during the tensile test experiments, proving unambiguously that the strength of the welds is stronger than that of the nanowires. It also proves the validity of the current welding technique in joining single crystal nanowires for tensile testing experiments. Besides evaluating the mechanical properties of nanomaterials in the TEM, this technique shows a great potential for the assembling of nanodevices, especially for fabricating or repairing ceramic nanodevices. In the future, it is possible that we could install such a device in the FIB equipment for achieving ceramic nanowelding using ceramic solder.

Similar to the welding of nanoceramic material, how to weld macroscopic ceramic is also a quite important but difficult task in industry. Inspired by the above experiment, we also explored the possibility of welding bulk ceramic materials using this technique via a macroscopic ceramic welding setup (Supplementary Fig. 22). In this study, we tried to weld ceramic $\mathrm{SiO}_{2}$ fibers onto a $\mathrm{Si}$ wafer, which are widely used materials in semiconductor industry. It is known that plasma can be formed from gas molecules under ebeam irradiation, thus we generated a $\mathrm{CO}_{2}$ plasma atmosphere in the chamber to promote the carbonation of $\mathrm{MgO}$ (Supplementary Fig. 23). The pristine $\mathrm{MgO}$ nanowires used for the macroscopic experiment were the same nanowires used in the in situ ETEM study. It was found that the $\mathrm{MgO}$ nanowires displayed a similar melting behavior as that observed in the ETEM (Supplementary Fig. 24). We found that a macroscopic ceramic $\mathrm{SiO}_{2}$ fiber was firmly welded onto the $\mathrm{Si}$ wafer by using this technique (Supplementary Fig. 25 and Supplementary Movie 9). A fast chemical reaction between $\mathrm{CO}_{2}$ and $\mathrm{MgO}$ at the macroscopic level took place in the chamber, similar phenomenon and byproduct was found as that observed in the ETEM study. The realization of plasma-assisted $\mathrm{CO}_{2}$ reaction with $\mathrm{MgO}$ at a macroscopic scale has important practical significance for the ceramic industry, as welding ceramics using ceramic solder becomes possible.

\section{Discussion}

A novel ceramic nanowelding technology based on the chemical reaction $\mathrm{MgO}+\mathrm{CO}_{2} \rightarrow \mathrm{MgCO}_{3}$ induced by e-beam irradiation is reported. The as-formed $\mathrm{MgCO}_{3}$ decomposes to nanocrystalline $\mathrm{MgO}$ with release of $\mathrm{CO}_{2}$ gas under e-beam irradiation. The formation of dense nanocrystalline $\mathrm{MgO}$ on the weld junction contributes to the strong mechanical properties of the rejoined nanowire. The mechanical strength of the weld junction can reach over $2.8 \mathrm{GPa}$. The technology can be used to weld ceramic nanowires and to enable in situ tensile test of individual nanowires. The technology can be used in the welding of not only nanoscale ceramics but also macroscopic ceramic material, showing a great application potential of this technology to industry.

\section{Methods}

The welding of ceramic nanomaterials. $\mathrm{MgO}$ nanowires were synthesized by a hydrothermal method, and the detailed fabrication process is discussed in the supporting information method 1. The TEM samples were prepared by adhering $\mathrm{MgO}$ nanowires onto $\mathrm{W}$ or $\mathrm{Al} \mathrm{STM}$ probes and then loading the probes into the TEM-STM (Pico Femto FE-F20). The movement of the sample was manipulated by the piezo-electric tube of the holders. When the nanowires were connected, high-purity $\mathrm{CO}_{2}(99.99 \%)$ was introduced the specimen chamber with a pressure of $200 \mathrm{~Pa}$. Upon the presence of $\mathrm{CO}_{2}$ and e-beam irradiation, a welding process started immediately. When the welding interfaces vanished, we pumped out the $\mathrm{CO}_{2}$ from the ETEM chamber and continued with e-beam irradiation of the nano welds. After that we found that the microstructure of the welds turned from amorphous $\mathrm{MgCO}_{3}$ into nanocrystalline $\mathrm{MgO}$. In order to quantitatively measure the mechanical strength of the weld junctions and carry out tensile tests for some other ceramic nanowires, we inserted a silicon AFM cantilever beam $(K=40 \mathrm{~N} \mathrm{~m}$

${ }^{-1}$ ) into one end of the TEM-STM holder which could be used as a TEM-AFM device. Because the deflection of the cantilever was much smaller than its beam length, a linear relationship between DD (displacement of the AFM tip, equal to the cantilever deflection) and $\mathrm{F}$ (force applied on the nanowire sample) was assumed. Attachment of the sample to the AFM cantilever was carried out using this welding technique and $\mathrm{MgO}$ was selected as the solder. During the experiment, a beam blocking bar was inserted into the field of view as the reference for displacement measurements. The tensile strength was calculated as engineering stress. The stress calculation was reasonably accurate $(<+10 \%$ error $)$ by measuring cantilever deflections in high magnification TEM images. The in situ welding experiment was 
conducted in a Cs-corrected environmental TEM (FEI, Titan ETEM, $300 \mathrm{kV}$ ). During the welding experiments, no current was passed through the sample, and the intensity of the e-beam was $0.02 \sim 0.2 \mathrm{~A} \mathrm{~cm}^{-2}$.

The welding of bulk ceramic materials. After the success of welding ceramic nanomaterial, we attempted this ceramic welding technique on macroscopic ceramics. Hydrothermal synthesized MgO powders were the same as that used for the TEM, and were put into a home-made glow discharge chamber. Upon the welding process, $\mathrm{CO}_{2}$ gas in high-purity $(99.99 \%)$ was introduced into the chamber and kept at $\sim 200 \mathrm{~Pa}$ for the generation of plasma. The discharge voltage was $500 \mathrm{~V}$, current $110 \mathrm{~mA}$, electrode space $\sim 1 \mathrm{~cm}$ and treatment time was $\sim 1 \mathrm{~h}$.

Data availability. The authors declare that all data supporting the findings of this study are available within the Article and its Supplementary Information files. Any other data will be provided by the corresponding author upon request.

Received: 24 July 2017 Accepted: 11 December 2017

Published online: 08 January 2018

\section{References}

1. Lu, W. \& Lieber, C. M. Nanoelectronics from the bottom up. Nat. Mater. 6, 841-850 (2007).

2. Xu, S. et al. Self-powered nanowire devices. Nat. Nanotechnol. 5, 366-373 (2010).

3. $\mathrm{Wu}$, J. et al. High electron mobility and quantum oscillations in nonencapsulated ultrathin semiconducting $\mathrm{Bi}_{2} \mathrm{O}_{2} \mathrm{Se}$. Nat. Nanotechnol. 12, 530-534 (2017).

4. Cui, Y. \& Lieber, C. M. Functional nanoscale electronic devices assembled using silicon nanowire building blocks. Science 291, 851-853 (2001).

5. Wang, X. et al. Graphene nanoribbons with smooth edges behave as quantum wires. Nat. Nanotechnnol. 6, 563-567 (2011).

6. Duan, X., Zhang, J., Ling, X. \& Liu, Z. Nano-welding by scanning probe microscope. J. Am. Chem. Soc. 127, 8268-8269 (2005).

7. Huang, J. \& Kaner, R. B. Flash welding of conducting polymer nanofibres. Nat. Mater. 3, 783-786 (2004)

8. Krasheninnikov, A. V. \& Banhart, F. Engineering of nanostructured carbon materials with electron or ion beams. Nat. Mater. 6, 723 (2007).

9. Wang, R. et al. Plasma-induced nanowelding of a copper nanowire network and its application in transparent electrodes and stretchable conductors. Nano Res. 9, 2138-2148 (2016).

10. Madsen, D. N. et al. Soldering of Nanotubes onto Microelectrodes. Nano. Lett. 3, 47-49 (2002).

11. Misra, A. \& Daraio, C. Sharp carbon-nanotube tips and carbon-nanotube soldering irons. Adv. Mater. 21, 2305-2308 (2010).

12. Garnett, E. C. et al. Self-limited plasmonic welding of silver nanowire junctions. Nat. Mater. 11, 241-249 (2012).

13. Kim, S. J. \& Jang, D. J. Laser-induced nanowelding of gold nanoparticles. Appl. Phys. Lett. 86, 711 (2005).

14. Lu, Y., Huang, J. Y., Wang, C., Sun, S. \& Lou, J. Cold welding of ultrathin gold nanowires. Nat. Nanotechnol. 5, 218 (2010).

15. Vafaei, A., Hu, A. \& Goldthorpe, I. A. Joining of Individual Silver Nanowires via Electrical Current. Nano-Micro Lett. 6, 293-300 (2014).

16. Ishida, T., Kakushima, K. \& Fujita, H. Gentle cold welding between gold nano objects driven by electrical field and atomic rearrangement. J. Appl. Phys. 110, 841 (2011).

17. Ke, Q. et al. Realization of the welding of individual $\mathrm{TiO}_{2}$ semiconductor nanoobjects by using novel $1 \mathrm{D} \mathrm{Au}_{80} \mathrm{Sn}_{20}$ nanosolder. J. Mater. Chem. C. 3, 11311-11317 (2015)

18. Aitkaliyeva, A., Madden, J. W., Miller, B. D. \& Cole, J. I. Implementation of focused ion beam (FIB) system in characterization of nuclear fuels and materials. Micron 67, 65-73 (2014).

19. Hilmas, G. E., Fahrenholtz, W. G., Watts, J. L. \& Brown-Shaklee, H. J. Ceramic welds, and a method for producing the same, U.S. Patent 8,715,803, (2014).

20. Bhagiyalakshmi, M., Ji, Y. L. \& Jang, H. T. Synthesis of mesoporous magnesium oxide: Its application to $\mathrm{CO}_{2}$ chemisorption. Int. J. Greenh. Gas. Con. 4, 51-56 (2010).

21. Jun, J., Kim, J.-C., Shin, J.-H., Lee, K.-W. \& Baek, Y. S. Effect of electron beam irradiation on $\mathrm{CO}_{2}$ reforming of methane over $\mathrm{Ni} / \mathrm{Al}_{2} \mathrm{O}_{3}$ catalysts. Radiat. Phys. Chem. 71, 1095-1101 (2004).
22. Choi, K. M. et al. Plasmon-Enhanced PhotoCatalytic $\mathrm{CO}_{2}$ Conversion within Metal Organic Frameworks under Visible Light. J. Am. Chem. Soc. 139, 356-362 (2017).

23. Valiev, R. Materials science: nanomaterial advantage. Nature 419, 887-889 (2002).

24. Meyers, M. A., Mishra, A. \& Benson, D. J. Mechanical properties of nanocrystalline materials. Prog. Mater. Sci. 51, 427-556 (2006).

25. Pan, S. Y., Chang, E. E. \& Chiang, P. C. $\mathrm{CO}_{2}$ capture by accelerated carbonation of alkaline wastes: a review on its principles and applications. Aerosol Air Qual. Res. 12, 770-791 (2012).

26. Willis, C., Boyd, A. W. \& Bindner, P. E. Carbon monoxide yields in the radiolysis of carbon dioxide at very high dose rates. Can. J. Chem. 48, 1951-1954 (1970).

27. Hansen, Wilum T. \& Wagner, Birkedal, J. Controlled Atmosphere Transmission Electron Microscopy Principles and Practice (Springer International Publishing, 2016).

28. Wang, Y., Li, T., Zhang, X., Zeng, H. \& Jin, Q. In situ TEM/SEM electronic/ mechanical characterization of nano material with MEMS chip. J. Semicond. 35, 081001 (2014)

29. Xu, T. T. et al. A platform for in situ multi-probe electronic measurements and modification of nanodevices inside a transmission electron microscope. Nanotechnology 25, 225702 (2014).

30. Howatson, A. M. Engineering tables and data. (Springer Science \& Business Media, 2012).

\section{Acknowledgements}

This work was financially supported by the National Natural Science Foundation of China (Nos. 51772262, 21576289, 51401239, 51071175, 51231005, 11575154 and 51621063), National Key Research and Development Program of China (No. 2017YFB0702001), the Science Foundation of China University of Petroleum, Beijing (No. C201603), the High-Level Talents Research Program of the Yanshan University (grant number 005000201) and Thousand Talents Program.

\section{Author contributions}

J.H., Z.S. and L.Z. conceived and designed the project. Y.T. and F.Y. fabricated the samples. L.Z., Y.T., Y.W., Q.L., T.Y., C.D. and Y.S. carried out the in situ ETEM experiments. J.H., T.S., L.C. and Q.P. supervised the experiments. J.H., L.Z., Y.L., and Z.S co-wrote the paper. L.Z. and Q.P. contribute equally to this work. All the authors discussed the results and commented on the manuscript.

\section{Additional information}

Supplementary Information accompanies this paper at https://doi.org/10.1038/s41467017-02590-1.

Competing interests: The authors declare no competing financial interests.

Reprints and permission information is available online at http://npg.nature.com/ reprintsandpermissions/

Publisher's note: Springer Nature remains neutral with regard to jurisdictional claims in published maps and institutional affiliations.

Open Access This article is licensed under a Creative Commons Attribution 4.0 International License, which permits use, sharing, adaptation, distribution and reproduction in any medium or format, as long as you give appropriate credit to the original author(s) and the source, provide a link to the Creative Commons license, and indicate if changes were made. The images or other third party material in this article are included in the article's Creative Commons license, unless indicated otherwise in a credit line to the material. If material is not included in the article's Creative Commons license and your intended use is not permitted by statutory regulation or exceeds the permitted use, you will need to obtain permission directly from the copyright holder. To view a copy of this license, visit http://creativecommons.org/ licenses/by/4.0/

(c) The Author(s) 2017 